\title{
Placebo response in migraine
}

\author{
Peer Tfelt-Hansen
}

Received: 14 September 2010 /Accepted: 4 November 2010 /Published online: 23 November 2010

(C) Springer-Verlag 2010

\section{Sir}

I am currently in the process of revising the Guidelines for Drug Trials in Migraine of The International Headache Society. While browsing the literature for information on the placebo response in migraine randomised clinical trials (RCTs), I read with interest the extensive meta-analysis on this subject published by Macedo et al. in the European Journal of Clinical Pharmacology [1]. There is, however, one fundamental misunderstanding in this article, namely, the definition of headache relief. These authors state that headache relief is a $50 \%$ reduction in pain [1]. The RCTs used the standard that all migraine sufferers should have moderate or severe headache pain before drug administration and that headache relief, as defined by Glaxo [2], was a decrease in headache pain from moderate (2) or severe (3) to none (0) or mild (1) at $1 \mathrm{~h}$ (subcutaneous sumatriptan) or $2 \mathrm{~h}$ (oral and intranasal triptans) post-drug administration. Therefore, successful headache relief could be assessed as $3-0$, $3-1,2-0$, or $2-1$.

The placebo response depends on many factors, such as study design, route of administration, and cultural elements (for example, Europe vs. North America [1]. In addition, an important determinant factor could also be whether the patients are treated as in-patients in headache clinics or whether they self-administer at home. In one crossover RCT in which a subcutaneous autoinjector with sumatriptan $6 \mathrm{mg}$ was used to treat migraine, patients were recruited from general practice and treated migraine attacks at home.
Headache relief was 61 and $6 \%$ at $60 \mathrm{~min}$ after the administration of the active drug and placebo, respectively [3]. The therapeutic gain (TG) was $55 \%$ (95\% confidence interval 44-65\%). Thus, the result obtained with the placebo was extremely low, but the TG was similar to the TG of 49 [1] and 51\% [4] reported in meta-analyses.

Finally, there is an increasing tendency to use pain free at $2 \mathrm{~h}$ as the primary efficacy measure in RCTs on acute treatment migraine [5], and pain free is what the migraine patients want to be [6].

\section{References}

1. Macedo A, Farré M, Baños J-E (2006) A meta-analysis of the placebo response in acute migraine and how this response may be influenced by some characteristics of clinical trials. Eur J Clin Pharmacol 62:161-172

2. Pilgrim A (1991) Methodology of clinical trials of sumatriptan in migraine and cluster headache. Eur Neurol 31:295-299

3. Jensen K, Tfelt-Hansen P, Hansen EW, Krøis EH, Pedersen OS (1995) Introduction of a novel selfinjector for sumatripta. A controlled clinical trial in general practice. Cephalalgia 15:423-429

4. Tfelt-Hansen P, De Vries P, Saxena PR (2000) Triptans in migraine. A comparative review of pharmacology, pharmacokinetics and efficacy. Drugs 60:1259-1287

5. Hougaard A, Tfelt-Hansen P (2010). Are the current IHS guidelines for migraine drug trials being followed? J Headache Pain. doi: 10.1007/s10194-010-0257-5

6. Lipton RB, Hamelsky SW, Dayo JM (2002) What do patients with migraine want from acute migraine treatment? Headache 42(Suppl $1): 3-9$

P. Tfelt-Hansen $(\bowtie)$

Danish Headache Center, Department of Neurology,

University of Copenhagen Glostrup Hospital,

Glostrup, Denmark

e-mail: ptha@glo.regionh.dk 